\title{
COMPRAS PÚBLICAS: UMA ANÁLISE DOS PROCESSOS LICITA- TÓRIOS HOMOLOGADOS NO MUNICÍPIO DE LONDRINA-PR
}

\author{
PUBLIC PURCHASING: AN ANALYSIS OF APPROVED BIDDING PROCESSES IN \\ LONDRINA-PR
}

\author{
Daniela Mayumi Yamaji \\ Universidade Estadual de Londrina, PR, Brasil \\ E-mail:danielamayumi7@gmail.com \\ Hilton Brito \\ Universidade Estadual de Londrina, PR, Brasil \\ E-mail: hbrito445@gmail.com \\ Vera Lucia Tieko Suguihiro \\ Universidade Estadual de Londrina, PR, Brasil \\ E-mail: suguihiro@uel.br \\ Juarez Paulo Tridapalli \\ Universidade Estadual de Londrina, PR, Brasil \\ E-mail: jtridapalli100@gmail.com \\ Saulo Fabiano Amâncio-Vieira \\ Universidade Estadual de Londrina, PR, Brasil \\ E-mail: saulofav@gmail.com
}

Recebido em: 05.12.2018 - Aceito em: 29.07.2019

DOI: http://dx.doi.org/10.5902/2526629236899

\section{RESUMO}

A administração pública municipal tem responsabilidade em alocar os recursos arrecadados e devolvê-los na forma de serviços prestados à população. Para tanto, o processo de compras deve ser gerido com afinco. O objetivo da pesquisa é avaliar a evolução dos processos licitatórios homologados do município de Londrina nos dois primeiros quadrimestres de 2017 e 2018. A pesquisa classifica-se como empírica, de abordagem quantitativa descritiva e estudo de caso. $\mathrm{O}$ método de coleta de dados é documental. Por meio de um Termo de Cooperação Técnica entre a Prefeitura Municipal de Londrina e a Universidade Estadual de Londrina, realiza-se um projeto na Secretaria de Gestão Pública, sendo que o presente estudo representa uma parcela deste. Comparam-se 284 processos licitatórios homologados na Secretaria de Gestão Pública, dos quais se averiguou- secretarias demandantes, prazos de tramitação, valores máximos e quantidade de itens homologados e malsucedidos. A pesquisa constatou que os prazos médios 
diminuíram e houve aumento no número de processos homologados por mês em 2018. Também houve aumento na economia gerada pelas licitações no período, sendo que em ambos os períodos se observou economia em relação ao total.

PALAVRAS-CHAVE: Compras públicas; Processos licitatórios; Processos homologados; Gestão pública municipal.

\section{ABSTRACT}

The municipal public administration has the responsability to allocate the collected resourses and return them in form of services provided to the population. Therefore, the purchasing process must be managed with consistence. The objective of the research is to evaluate the evolution of the approved bidding processes in the city of Londrina for the first two quarters of 2018 and 2017. The research is classified as empirical, with a descriptive quantitative approach and case stu$d y$, the method of data collection is documentary. Trought a Term of Thecnichal Cooperation between the City Hall of Londrina and the State University of Londrina, a project is carried out in the Department of Public Admministration, and the present study represents a portion of this. 284 approved bidding processes in the Department of Public Admministration were compared, from wich were verified the requesting departaments, processing deadlines, maximum values and number of approved but unsuccessful itens. The survey found that the average deadlines decreased and there was an incerease in the number of processes approved per month in 2018, there was also an increase in the savings generated by the bids in the period, and both periods decreased in relation to the total.

KEYWORDS: Public procurement; Bidding processes; Approved processes; Municipal public management.

\section{INTRODUÇÃO}

A administração pública é responsável pelo gerenciamento dos recursos arrecadados na forma de impostos (diretos e indiretos), a fim de manter o funcionamento da própria máquina pública e devolver parte desses recursos na forma de transferências ou serviços prestados à população, tais como saúde, educação e segurança. Para tal objetivo, são necessárias aquisições, por meio de compras públicas, de produtos (consumíveis ou permanentes) e contratos para serviços terceirizados.

Para Vignoli (2008), a descentralização dos recursos, garantida pela Constituição Federal de 1988, por meio da independência e competência tributária dos municípios, fez dos próprios municípios os maiores beneficiários, pois dessa for- 
ma há a melhor distribuição e retenção dos recursos nos locais em que serão utilizados. Ainda de acordo com Motta e Moreira (2007), o município pode ser considerado uma unidade produtiva, sobre a qual se pode medir sua eficiência em relação à qualidade de vida proporcionada aos seus cidadãos.

A atuação do Estado perpassa o surgimento e consolidação do capitalismo, sendo absoluto no primeiro momento, tornando-se liberal, neoliberal burocrático e, a partir do final do século XX, com a disseminação do movimento do $\mathrm{New} \mathrm{Pu-}$ blic Management e a reforma da gestão pública brasileira, tornou-se republicano. (Besser- Pereira, 2009). De acordo com Pieranti, Rodrigues e Peci (2007), as contribuições do movimento no Brasil compreendem a diminuição da máquina pública, a busca por eficiência e a responsabilização do setor público.

Municípios deparam-se com a dificuldade em gerenciar as compras públicas, especialmente os de médio porte, dentre os quais se encontra o município paranaense de Londrina, alvo deste estudo de caso. Observa-se que a administração pública do município atende não só os seus habitantes, mas também os cidadãos dos municípios vizinhos e região metropolitana, especialmente nos serviços de saúde. Porém, evidentemente, não são arrecadados recursos referentes a tal demanda, o que dificulta ainda mais a atuação do setor público e do setor de compras públicas de Londrina.

O estudo de Tridapalli et al (2018) realiza uma revisão bibliográfica de gestão de cadeia de suprimentos nos âmbitos internacional e nacional, seguido de um estudo de caso na cidade de Londrina, a fim de propor um modelo de gestão da cadeia de suprimentos para municípios de médio porte em países em desenvolvimento. O modelo estabelecido buscou agilidade, economicidade, transparência e redução dos custos operacionais, o que acarreta a eficiência das políticas públicas.

Compreende-se que há um baixo número de publicações sobre o processo de compra pública em si. Devido a isso, o presente trabalho pretende descrever o processo de compra pública como um todo, desde a solicitação até a homologação, para que sejam apurados os principais gargalos no que diz respeito a prazos e eficiência na obtenção de melhores preços.

O objetivo da pesquisa é avaliar a evolução dos processos licitatórios homologados do município de Londrina nos dois primeiros quadrimestres de 2017 e 2018. Foram estabelecidos como objetivos específicos: i) descrever os tipos de processos licitatório analisados no período, ii) definir as fases que o processo percorre até a homologação e iii) realizar uma análise estatística descritiva do objeto de análise. 
Essa pesquisa é uma parcela de um projeto ainda em andamento, estabelecido por meio de um Termo de Cooperação Técnica entre a Prefeitura Municipal de Londrina e a Universidade Estadual de Londrina, representada pelo NIGEP (Núcleo Interdisciplinar de Gestão Pública), com o intuito de otimizar os processos licitatórios que tramitam na Secretaria de Gestão Pública.

\section{REFERENCIAL TEÓRICO}

Nos próximos tópicos apresentam-se aspectos teóricos e empíricos sobre o New public management (movimento que aplica modelos de gestão do setor privado no setor público, compras públicas), a disposição legal da lei $n^{\circ} 8.666$ de 1993 e suas implicações no setor público municipal.

\subsection{New public management}

O movimento, nas décadas de 1970 e 1980, nos Estados Unidos e Europa, surgiu nas relações entre setor público e privado ao inserir conhecimentos e práticas gerenciais da administração à gestão pública, redesenhando os limites e responsabilidades do Estado, as organizações privadas e a sociedade civil organizada (Blonski et al, 2017; Pieranti, Rodrigues \& Penna, 2007). Esse movimento inseriu-se no Brasil entre 1995 e 1998, a partir do Plano Diretor da Reforma do Aparelho do Estado, implantado pelo Ministério do Planejamento, Desenvolvimento e Gestão durante o primeiro governo do ex-presidente Fernando Henrique Cardoso. A reforma da gestão pública brasileira foi conhecida inicialmente como "reforma gerencial do Estado" (Bresser-Pereira, 2009).

A administração pública gerencial (NPM) opõe-se ao modelo burocrático weberiano - em que se priorizava o modo rígido com que as tarefas eram realizadas, isto é, a formalidade, a impessoalidade e o profissionalismo, pois se baseia em valores de eficiência, eficácia e competitividade (Secchi, 2009).

Osborne (2006) compara três paradigmas da administração do setor público: Public Administration (PA), movimento teórico do pós Segunda Guerra; o New Public Management (NPM) e a New Public Governance (NPG). A discussão sobre esta iniciou-se nos anos 90 , sendo que as duas diferenciam-se, entre outros fatores, por suas raízes teóricas (ciência política, estudos administrativos e sociologia educacional, respectivamente); por seu foco (sistema político, gerência intraorganizacional e governança interorganizacional, respectivamente) e por seus valores base (ética do setor público, eficácia da competitividade e neocorporativista). 
Entre algumas dicotomias discutidas por Pieranti, Rodrigues e Peci (2007) a respeito do modelo do New Public Management e da New Public Governance estão: administração e política, autonomia e dependência, cliente e cidadão. $O$ conflito entre administração e política dá-se devido ao pressuposto do NPM de eficiência e neutralidade da figura e atuação do administrador, o que de fato não ocorre e é alvo de inúmeras críticas no Brasil, que ainda tende a ceder ao clientelismo dos governantes.

A defesa da autonomia ou da dependência aparta opiniões no Brasil, acarretando um ciclo de políticas de centralização e descentralização. A autonomia e a descentralização por vezes caracterizam, para alguns, perda de controle e demasiada desburocratização, diminuição do orçamento e negligência do Estado, enquanto a dependência e a centralização conotam burocracia, morosidade e desperdício de tempo e recursos.

Por último, a dicotomia entre cliente e cidadão discutida por Pieranti, Rodrigues e Peci (2007) esclarece a relação que o indivíduo atendido pelo Estado administrado por essa nova gestão pública não é apenas um cliente ou apenas um cidadão, mas um cliente-cidadão que tem direitos assegurados por lei que transpassam os direitos de um consumidor do setor privado.

[...] a discussão de políticas para melhorar a gestão do setor público ainda não alcançou a prioridade necessária nem no âmbito do próprio governo e nem no âmbito da sociedade, provavelmente porque ambos a consideram uma dimensão secundária frente às prioridades de políticas públicas setoriais e da política econômica que ocupam agenda e espaço de discussão pública (Pieranti, Rodrigues \& Peci, 2007, p. 14).

No referido estudo, Pieranti, Rodrigues e Peci (2007) concluem que, apesar de iniciada, a reforma na gestão pública ainda não alcançou o seu ponto ideal na sociedade brasileira em virtude da falta de conhecimento da administração clássica. Além disso, o modelo de gestão do setor público deve ser constantemente repensado e adaptado à realidade atual, sempre que necessário, como também ressalta Bresser-Pereira (2009, p. 263): "Em administração, o que é certo hoje pode se tornar obsoleto amanhã: novos fatos, ou a simples desorganização ou entropia dos já existentes, exigem continuamente novas decisões executivas.".

Desta maneira, à luz dos estudos do movimento do New Public Management, a administração pública procura aprimorar a gestão dos processos licitatórios, isto é, as compras públicas, sobre as quais se discorre a seguir. 


\subsection{Compras públicas}

As normas para licitações e contratos da administração pública estão previstas na Lei $n^{\circ} 8.666$ de 21 de junho de 1993, que regulamenta o art.37, inciso XXI da Constituição Federal de 1988. A referida lei descreve os entes subordinados desta, os princípios, as modalidades, os prazos legais, os procedimentos a serem observados, o julgamento das propostas, a celebração de contratos, as possibilidades de recurso, os crimes e as penas relacionados às compras públicas, as quais devem estar:

[...] em estrita conformidade com os princípios básicos da legalidade, impessoalidade, moralidade, igualdade, da publicidade, da probidade administrativa, da vinculação ao instrumento convocatório, do julgamento objetivo e dos que lhes são correlatos. (Lei $\mathrm{n}^{\circ} 8.666$, art.3 ${ }^{\circ}, 1993$, p.13).

Complementarmente à Lei $\mathrm{n}^{\circ}$ 8.666, tem-se diferentes dispositivos legais que auxiliam na implementação destes processos, tais como a Lei nacional $n^{\circ}$ 10.520/02, que institui o pregão, em especial o pregão eletrônico, que antes era restrito à União, e a lei estadual $n^{\circ} 15.608 / 07$.

O estudo de Ribeiro e Inácio Júnior (2014) mensura o montante gasto com compras públicas no período de 2016 e 2012 no Brasil, concluindo que estas representam em torno de $13,8 \%$ do PIB brasileiro. De acordo com os autores, compras públicas são, além de prestar serviços à comunidade, uma maneira de estimular o desenvolvimento industrial, comercial e tecnológico local sem ferir tratados comerciais entre Estados (RIBEIRO; INÁCIO JÚNIOR, 2014).

Os resultados demonstram que o maior dispêndio em compras públicas é realizado primeiramente pela União, com representatividade média de 8,05\% do PIB, e em segundo lugar pelos municípios, com média para o período de $3,65 \%$, e por último pelos Estados, com 2,5\% do PIB.

Dada a importância na participação dos municípios na gestão dos recursos públicos, Tridapalli e Borinelli (2015) afirmam que estes têm maior dificuldade de gerar economia de escala por algumas razões, tais como: lidar com a grande diversidade de produtos e serviços e com a baixa capacidade administrativa em comparação aos Estados e a União, além da tendência destes em apresentar cultura patrimonial e clientelista, o que acarreta privatização dos recursos públicos.

Faria et al (2010) avaliaram, baseados na Teoria dos Leilões, a correlação linear entre as variáveis: número de fornecedores, especificidade do objeto, frequência da transação e quantidade com a obtenção de menores preços nas compras 
via pregão eletrônico. Os pesquisadores afirmaram haver correlação significativa e positiva entre o número de fornecedores interessados, a frequência de compra, de quantidade e de preços mais vantajosos, enquanto a especificação do objeto resultou em menor vantagem para o ente público. Recomendou-se que a gestão invista em meios de promover os pregões, para que assim haja maior número de empresas fornecedoras interessadas, bem como para agrupar demandas para aumentar a quantidade do objeto a ser comprado. Com relação à frequência, deve-se, segundo Faria et al (2010), estabelecer um relacionamento e incentivo às empresas participarem das licitações.

\section{PROCEDIMENTOS METODOLÓGICOS}

\subsection{Classificação da pesquisa}

A pesquisa caracteriza-se como do tipo empírica, pois houve coleta e tratamento de dados. A abordagem é quantitativa, pois há utilização de estatística descritiva no processamento dos dados, e é também descritiva, pois realiza um diagnóstico direto e objetivo das informações coletadas (Richardson et al., 2015), isto é, dos tipos, modalidades e prazos dos processos administrativos licitatórios municipais, apresentando a relação entre estas variáveis. É um estudo de caso, que, de acordo com Yin (2005, p. 32), "investiga um fenômeno contemporâneo dentro de seu contexto" e caracteriza-se pela dificuldade de distinção entre o contexto e o fenômeno.

Por último, o método de coleta de dados é documental. Houve coleta de dados secundários, já que a pesquisadora teve acesso aos documentos eletrônicos pertinentes à tramitação dos processos licitatórios (Maeconi \& Lakatos, 2003).

\subsection{Unidade de análise}

A unidade de análise desta pesquisa compreende 248 processos licitatórios homologados dos dois primeiros quadrimestres de 2017 e de 2018, isto é, de janeiro a agosto, no município de Londrina.

A coleta de dados realizou-se por meio do acesso ao Sistema Eletrônico de Informações (SEI) do município, no qual, desde 2017, os processos licitatórios são tramitados e assinados eletronicamente. A pesquisadora obteve um login de usuário do SEI autorizado pela Prefeitura. O SEI é um software de gestão de documentos e processos eletrônicos desenvolvido pelo Tribunal Regional Federal da $4^{a}$ Região. Sua implementação iniciou-se em 2009 no TRF4 (Memoria TRF4, 
2014), estendendo-se posteriormente aos Estados e Municípios (Minstério da Fazenda, 2017).

\subsection{Procedimento de coleta de dados}

Estabeleceu-se um modelo de planilha do Microsoft Excel para coletar tipo, modalidade, objeto solicitado, secretaria demandante, valor máximo, valor homologado, quantidade de itens homologados e fracassados ou desertos, conforme exibe a Imagem 1.

Imagem 1- Recorte de Planilha 1

\begin{tabular}{|c|c|c|c|c|c|c|c|}
\hline N Processo SII & N'Pregin & Objeto & Valar do Felital & Valor Hortalogado & Quantidade de irens & $\begin{array}{c}\text { Quantidade de itens } \\
\text { mal-sucedidos }\end{array}$ & Demandante \\
\hline 19.008 .0191382016 .14 & $231 / 2016$ & $\begin{array}{l}\text { Aquasi; io de equipamentos, } \\
\text { utensilos drersos e mobilano }\end{array}$ & RS $\quad 185.469,10$ & $115.689,45$ & 45 & 10 & SMI \\
\hline 190080003602017.16 & $7 / 2017$ & $\begin{array}{l}\text { Registro de prejos para eventual } \\
\text { aquasi,jo dos Generos Almenticios }\end{array}$ & RS $\quad 8599215,74$ & RS $\$ 954055,00$ & 92 & 0 & SMI \\
\hline
\end{tabular}

Fonte: os autores, 2018.

Os tipos de processos considerados para a pesquisa são: calendário de compras, obras, objeto específico e registro de preço. Calendário de compras são licitações iniciadas pela Secretaria Municipal de Gestão Pública (SMGP), em que há uma categoria geral de objetos a serem comprados, os quais todas as secretarias podem requisitar na quantidade necessitada, realizando uma aquisição direta após a homologação. Processos de Obras são geralmente demandados pela Secretaria Municipal de Obras e Pavimentação (SMOP) e compreendem contratação de empresas para elaboração de projetos ou realização de obras.

Processos de Objeto Específico são em sua maioria solicitados por uma única secretaria, e o objeto é relacionado com a atribuição do órgão. Registro de Preços são processos em que há uma possibilidade de aquisição do objeto licitado, ou seja, não há obrigatoriedade da sua aquisição. As modalidades constituem-se de: pregão presencial, pregão eletrônico, convite, tomada de preços, concorrência, dispensa de licitação e inexigibilidade.

Os prazos das etapas do processo são coletados, conforme Imagem 2. O trâmite do processo licitatório na SMGP foi dividido em sete fases, também conforme a Imagem 2: i) realização de check-list: prazo entre a entrada do processo no sistema até a elaboração de check-list pela Diretoria de Gestão de Licitações e Contratos; ii) abertura de PAL - Processo Administrativo Licitatório: prazo entre check-list e autorização de abertura de PAL pelo Secretário de Gestão Pública; iii) 
solicitação de consulta jurídica na PGM - Procuradoria Geral do Município: prazo entre a autorização do PAL e encaminhamento para PGM; iv) parecer jurídico: liberação da Procuradoria por meio do Despacho Terminativo; v) prazo para publicação do edital: publicação do edital do JOM - Jornal Oficial do Município; vi) prazo entre publicação e certame: dias entre a publicação do edital no JOM e o certame dos lotes; e vii) prazo entre certame e homologação: dias entre o certame e a assinatura da homologação pelo Secretário de Gestão Pública. Por último, somam-se as fases e obtêm-se o prazo total dos processos.

Imagem 2- Recorte de Planilha 2

\begin{tabular}{c|c|c|c|c|c|c|c|}
\hline $\begin{array}{c}\text { Prazo Total } \\
\text { dos }\end{array}$ & $\begin{array}{c}\text { Realização } \\
\text { de check-list } \\
\text { FP }\end{array}$ & $\begin{array}{c}\text { Abertura de PAL } \\
\text { (FP e TR) }\end{array}$ & $\begin{array}{c}\text { Elaboração de } \\
\text { minuta edital e ata } \\
\text { (solicitação PGM) }\end{array}$ & $\begin{array}{c}\text { Parecer } \\
\text { juridico }\end{array}$ & $\begin{array}{c}\text { Finalização do } \\
\text { edital } \\
\text { (publicação) }\end{array}$ & $\begin{array}{c}\text { Prazo entre } \\
\text { publicação e } \\
\text { certame }\end{array}$ & $\begin{array}{c}\text { Prazo entre o } \\
\text { certame e a } \\
\text { homologação }\end{array}$ \\
\hline
\end{tabular}

Fonte: os autores, 2018.

Os processos homologados, tanto de 2017 quanto de 2018, foram listados e enviados à pesquisadora pela assessora do secretário de Gestão Pública do Município de Londrina-PR, por meio do qual se obtinham os respectivos números de cadastro no SEI, obtendo-se, assim, o acesso aos documentos digitais nele anexados.

\subsection{Procedimento de análise dos dados}

A pesquisa utiliza análise quantitativa dos dados por meio da estatística descritiva, a qual se adéqua ao objetivo do estudo por permitir ao pesquisador observar as relações de média, de variação e de comparação entre os valores dos grupos amostrais, com auxílio do software Microsoft Excel. Por meio dos valores absolutos, das médias e das taxas de variação das variáveis escolhidas, são realizadas comparações entre as categorias e entre os períodos, a fim de descrever a evolução dos processos homologados nos dois primeiros quadrimestres dos anos de 2017 e 2018.

\section{APRESENTAÇÃO E ANÁLISE DOS DADOS}

Nas próximas seções, apresentam-se os dados organizados de acordo com a categoria e a variável analisada, juntamente à discussão a que se pôde chegar de acordo com os objetivos estabelecidos e o subsídio teórico escolhido. 


\subsection{Quantidade de processos}

Os processos foram classificados em quatro categorias: Calendário, Objeto específico, Processos de obras e Registro de preço. As quantidades de processos, por categoria e por mês, e o total de janeiro a agosto dos dois anos estão expostos nas Tabelas 1 e 2 a seguir.

Tabela 1-Total de Processos de 2017

\begin{tabular}{c|cccccccc|c|c}
\hline Tipo & Jan & Fev & Mar & Abr & Mai & Jun & Jul & Ago & Total & Total (\%) \\
\hline Calendário & 0 & 1 & 1 & 1 & 0 & 2 & 0 & 1 & $\mathbf{6}$ & $\mathbf{7 \%}$ \\
Objeto específico & 6 & 0 & 8 & 7 & 4 & 2 & 7 & 7 & $\mathbf{4 1}$ & $\mathbf{4 6 \%}$ \\
Obras & 2 & 0 & 1 & 2 & 1 & 3 & 0 & 1 & $\mathbf{1 0}$ & $\mathbf{1 1 \%}$ \\
Registro de preços & 2 & 3 & 2 & 4 & 1 & 6 & 11 & 4 & $\mathbf{3 3}$ & $\mathbf{3 7 \%}$ \\
\hline Total & $\mathbf{1 0}$ & $\mathbf{4}$ & $\mathbf{1 2}$ & $\mathbf{1 4}$ & $\mathbf{6}$ & $\mathbf{1 3}$ & $\mathbf{1 8}$ & $\mathbf{1 3}$ & $\mathbf{9 0}$ & $\mathbf{1 0 0 \%}$ \\
\hline Total (\%) & $\mathbf{1 1 \%}$ & $\mathbf{4 \%}$ & $\mathbf{1 3 \%}$ & $\mathbf{1 6 \%}$ & $\mathbf{7 \%}$ & $\mathbf{1 4 \%}$ & $\mathbf{2 0 \%}$ & $\mathbf{1 4 \%}$ & $\mathbf{1 0 0 \%}$ &
\end{tabular}

Fonte: os autores, 2018.

Tabela 2-Total de Processos em 2018

\begin{tabular}{c|cccccccc|c|c}
\hline \multicolumn{10}{c}{2018} \\
\hline Tipo & Jan & Fev & Mar & Abr & Mai & Jun & Jul & Ago & Total & Total (\%) \\
\hline Calendário & 4 & 3 & 5 & 1 & 3 & 2 & 5 & 2 & $\mathbf{2 5}$ & $\mathbf{1 3 \%}$ \\
Objeto específico & 5 & 10 & 15 & 14 & 7 & 21 & 24 & 13 & $\mathbf{1 0 9}$ & $\mathbf{5 6 \%}$ \\
Obras & 0 & 0 & 6 & 4 & 5 & 2 & 4 & 4 & $\mathbf{2 5}$ & $\mathbf{1 3 \%}$ \\
Registro de preços & 11 & 1 & 5 & 4 & 2 & 5 & 2 & 5 & $\mathbf{3 5}$ & $\mathbf{1 8 \%}$ \\
\hline Total & $\mathbf{2 0}$ & $\mathbf{1 4}$ & $\mathbf{3 1}$ & $\mathbf{2 3}$ & $\mathbf{1 7}$ & $\mathbf{3 0}$ & $\mathbf{3 5}$ & $\mathbf{2 4}$ & $\mathbf{1 9 4}$ & $\mathbf{1 0 0 \%}$ \\
\hline Total (\%) & $\mathbf{1 0 \%}$ & $\mathbf{7 \%}$ & $\mathbf{1 6 \%}$ & $\mathbf{1 2} \%$ & $\mathbf{9 \%}$ & $\mathbf{1 5 \%}$ & $\mathbf{1 8 \%}$ & $\mathbf{1 2 \%}$ & $\mathbf{1 0 0 \%}$ & \\
\hline
\end{tabular}

Fonte: os autores, 2018.

Observa-se que a maior parte dos processos, quando relacionados aos períodos de 2017 e de 2018, são de Objeto Específico, com 46\% e 56\% das licitações, respectivamente, isto é, representam demandas exclusivas de uma secretaria municipal solicitante. Logo em seguida, está o Registro de Preços, com 37\% e 18\% das licitações homologadas, respectivamente. Os tipos Calendário e Obras têm menor frequência, com variação de $7 \%$ para $13 \%$ e de $11 \%$ para $13 \%$, respectivamente.

A quantidade de processos homologados de janeiro a agosto de 2017 é menor do que em 2018, sendo que este representa $68,09 \%$ do universo avaliado e aquele, consequentemente, representa $31,91 \%$ do total. Esse comportamento do volume de processos manteve-se constante nos quatro meses analisados. Isto é, em todos os meses o número de processos homologados é maior em 2018 do que em 2017, conforme mostra o Gráfico 1. 


\section{TOTAL DE PROCESSOS POR MÊS}

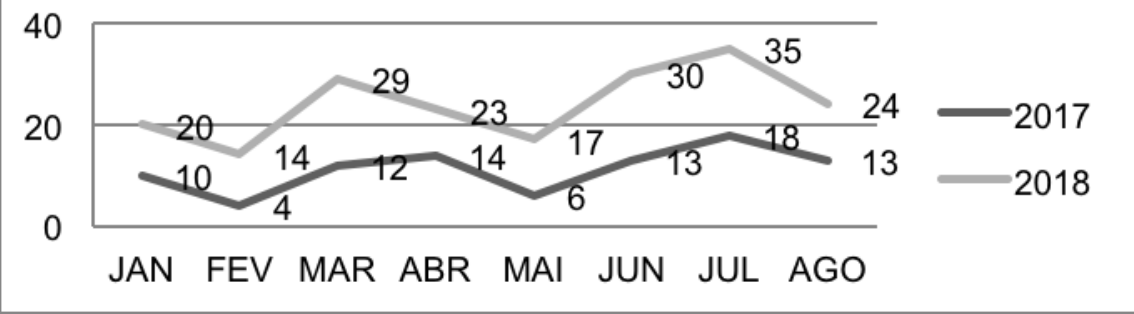

Fonte: os autores, 2018.

Observa-se uma sazonalidade no volume de processos homologados ao longo do período de análise, de acordo com as curvas de 2017 e 2018, que estão aparentemente paralelas em todos os meses. Há uma queda no número de processos em Janeiro a Fevereiro, Abril a Maio e Julho a Agosto. Sendo que de Fevereiro a Março e Maio a Julho são períodos de aumento em ambos os anos.

\subsection{Fases dos processos}

Analisam-se, a seguir, as médias em dias que os processos tramitam por cada uma das sete fases, desde a solicitação à homologação, considerando os quatro diferentes tipos de processos licitatórios. A Tabela 3 refere-se ao ano de 2017 e a Tabela 4 ao de 2018.

Tabela 3- Duração de cada fase dos processos por mês em 2017

\begin{tabular}{c|ccccccc|c}
\hline 2017 & $\begin{array}{c}\text { Reali- } \\
\text { zação } \\
\text { de che- } \\
\text { ck-list }\end{array}$ & $\begin{array}{c}\text { Aber- } \\
\text { tura } \\
\text { de } \\
\text { PAL }\end{array}$ & $\begin{array}{c}\text { Prazo } \\
\text { para } \\
\text { Solicita- } \\
\text { ção na } \\
\text { PGM }\end{array}$ & $\begin{array}{c}\text { Pare- } \\
\text { cer ju- } \\
\text { rídico }\end{array}$ & $\begin{array}{c}\text { Prazo } \\
\text { para pu- } \\
\text { blicação } \\
\text { do edital }\end{array}$ & $\begin{array}{c}\text { Prazo } \\
\text { entre } \\
\text { publica- } \\
\text { ção e } \\
\text { certame }\end{array}$ & $\begin{array}{c}\text { Prazo } \\
\text { entre o } \\
\text { certame e } \\
\text { a homolo- } \\
\text { gação }\end{array}$ & $\begin{array}{c}\text { Prazo } \\
\text { Total dos } \\
\text { Proces- } \\
\text { sos }\end{array}$ \\
\hline Jan & 20 & 30 & 41 & 25 & 47 & 31 & 48 & 221 \\
Fev & 29 & 20 & 59 & 16 & 46 & 32 & 33 & 205 \\
Mar & 58 & 85 & 9 & 25 & 12 & 21 & 34 & 186 \\
Abr & 15 & 52 & 28 & 23 & 12 & 24 & 44 & 183 \\
Mai & 27 & 53 & 10 & 42 & 25 & 39 & 44 & 206 \\
Jun & 43 & 62 & 21 & 36 & 7 & 30 & 28 & 181 \\
Jul & 24 & 56 & 9 & 31 & 7 & 24 & 45 & 172 \\
Ago & 21 & 30 & 2 & 29 & 19 & 38 & 86 & 167 \\
\hline Média & $\mathbf{2 9}$ & $\mathbf{4 8}$ & $\mathbf{2 2}$ & $\mathbf{2 8}$ & $\mathbf{2 2}$ & $\mathbf{3 0}$ & $\mathbf{4 5}$ & $\mathbf{1 9 0}$ \\
\hline
\end{tabular}

Fonte: os autores, 2018. 
Os prazos mais longos no ano de 2017 são o de abertura de PAL, com média de 48 dias, e o prazo entre o certame e a homologação, com média de 45 dias. Os menores prazos são para solicitação na PGM (Procuradoria Geral do Município) e para publicação do edital, ambos se apresentam com média de 22 dias. A média do prazo total dos processos nesse ano é de 190 dias.

Tabela 4- Duração de cada fase dos processos por mês em 2018

\begin{tabular}{c|ccccccc|c}
\hline 2018 & $\begin{array}{c}\text { Realiza- } \\
\text { ção de } \\
\text { check } \\
\text {-list }\end{array}$ & $\begin{array}{c}\text { Aber- } \\
\text { tura } \\
\text { de }\end{array}$ & $\begin{array}{c}\text { PAL } \\
\text { para } \\
\text { Solicita- } \\
\text { ção na } \\
\text { PGM }\end{array}$ & $\begin{array}{c}\text { Pa- } \\
\text { recer } \\
\text { jurídi- } \\
\text { co }\end{array}$ & $\begin{array}{c}\text { Prazo } \\
\text { para pu- } \\
\text { blicação } \\
\text { do edital }\end{array}$ & $\begin{array}{c}\text { Prazo } \\
\text { entre pu- } \\
\text { blicação e } \\
\text { certame }\end{array}$ & $\begin{array}{c}\text { Prazo } \\
\text { entre o } \\
\text { certame e } \\
\text { a homolo- } \\
\text { gação }\end{array}$ & $\begin{array}{c}\text { Prazo } \\
\text { Total dos } \\
\text { Proces- } \\
\text { sos }\end{array}$ \\
\hline JAN & 38 & 112 & 8 & 43 & 7 & 18 & 46 & 234 \\
FEV & 28 & 42 & 26 & 14 & 12 & 23 & 19 & 148 \\
MAR & 48 & 81 & 20 & 16 & 8 & 18 & 19 & 163 \\
ABR & 24 & 48 & 44 & 34 & 21 & 21 & 34 & 202 \\
MAI & 28 & 57 & 8 & 20 & 4 & 18 & 21 & 126 \\
JUN & 23 & 53 & 11 & 25 & 6 & 16 & 17 & 128 \\
JUL & 30 & 45 & 11 & 18 & 5 & 15 & 13 & 107 \\
AGO & 31 & 58 & 9 & 14 & 7 & 14 & 23 & 123 \\
\hline MÉDIA & $\mathbf{3 1}$ & $\mathbf{6 2}$ & $\mathbf{1 7}$ & $\mathbf{2 3}$ & $\mathbf{9}$ & $\mathbf{1 8}$ & $\mathbf{2 4}$ & $\mathbf{1 5 4}$ \\
\hline
\end{tabular}

Fonte: os autores, 2018.

A Tabela 4 mostra os prazos médios das fases dos processos de compra, sendo que, com exceção da Abertura de PAL, em todas elas houve diminuição da média. Observa-se que a média do prazo total dos processos é de 154 dias, o que representa uma diferença de 36 dias em relação a 2017.

No Gráfico 2, comparam-se os prazos médios das fases de 2017 e 2018. Constata-se que houve diminuição na média dos prazos totais dos processos, porém nem todas as fases do processo apresentaram melhora. 


\section{Gráfico 2- Prazo médio dos processos (em dias)}

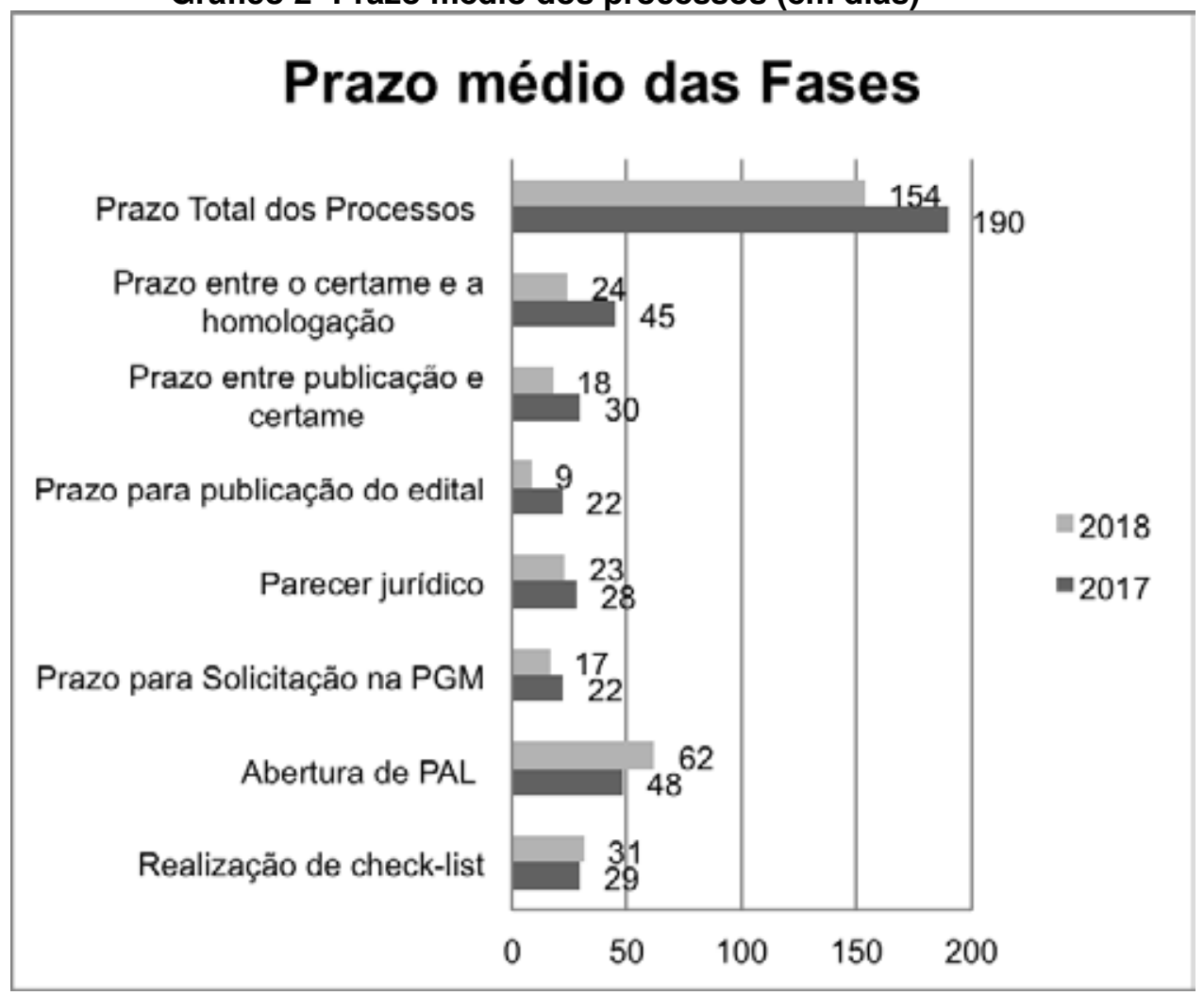

Fonte: os autores, 2018.

A realização de check-list e de abertura de PAL apresentam aumento no prazo médio 22 e 24 dias, respectivamente. O prazo entre o certame e a homologação (que em 2017 apresenta a maior média) foi o que obteve maior diminuição, passando de 45 para 27 dias em média.

\subsection{Economia em relação ao valor máximo do edital}

A economia gerada pelo processo licitatório é calculada por meio da comparação entre o valor máximo estimado pelo edital, que é elaborado pela Comissão de Formação de Preço (CFP) na Diretoria de Gestão de Licitações e Contratos (DGLC), e o valor acertado por meio da adjudicação no certame, que é homologado pelo secretário de gestão pública e liberado para empenho na Secretaria de Fazenda do município.

As Tabelas 5 e 6 apresentam a economia monetária total entre o valor do edital e o valor homologado dos anos de 2017 (corrigidos pelo IPCA deste ano) e 2018 de acordo com o tipo de processo. As colunas de diferença entre os valores de edital e de homologado exibem as taxas de variação percentual entre os dois valores. 
Tabela 5- Economia nos certames e diferença percentual em 2017

\begin{tabular}{|c|c|c|c|c|}
\hline Tipo & Valor do Edital & Valor Homologado & Diferença & Diferença (\%) \\
\hline Calendário & $\mathrm{R} \$ 17.989,21$ & $\mathrm{R} \$ 13.299,15$ & $\mathrm{R} \$ 4.690,06$ & $-26,07 \%$ \\
\hline $\begin{array}{l}\text { Objeto Es- } \\
\text { pecífico }\end{array}$ & $\mathrm{R} \$ 1.484 .803,42$ & $\mathrm{R} \$ 1.165 .130,69$ & $R \$ 319.672,73$ & $-21,53 \%$ \\
\hline Obras & $R \$ 297.962,42$ & $R \$ 252.402,10$ & $R \$ 45.560,32$ & $-15,29 \%$ \\
\hline $\begin{array}{l}\text { Registro de } \\
\text { Preços }\end{array}$ & $\mathrm{R} \$ 985.164,51$ & $\mathrm{R} \$ 644.298,62$ & $R \$ 340.865,89$ & $-34,60 \%$ \\
\hline Total & R\$ 2.785.919,56 & R\$ 2.075.130,55 & $\mathrm{R} \$ 710.789,01$ & $-25,51 \%$ \\
\hline
\end{tabular}

Fonte: os autores, 2018.

Tabela 6- Economia nos certames e diferença percentual em 2018

\begin{tabular}{|c|c|c|c|c|}
\hline Tipo & Valor do Edital & Valor Homologado & Diferença & $\begin{array}{c}\text { Diferença } \\
(\%)\end{array}$ \\
\hline Calendário & $\mathrm{R} \$ 3.770 .089,08$ & $\mathrm{R} \$ 2.729 .633,50$ & $R \$ 1.040 .455,58$ & $-27,60 \%$ \\
\hline $\begin{array}{c}\text { Objeto } \\
\text { Específico }\end{array}$ & $\mathrm{R} \$ 81.588 .115,19$ & $\mathrm{R} \$ 69.476 .816,01$ & $\begin{array}{c}\mathrm{R} \$ \\
12.111 .299,18\end{array}$ & $-14,84 \%$ \\
\hline Obras & $\mathrm{R} \$ 42.689 .741,57$ & $R \$ 35.088 .235,36$ & $\mathrm{R} \$ 7.601 .506,21$ & $-17,81 \%$ \\
\hline $\begin{array}{c}\text { Registro de } \\
\text { Preços }\end{array}$ & $\mathrm{R} \$ 28.539 .251,98$ & $\mathrm{R} \$ 17.265 .650,43$ & $\begin{array}{c}\mathrm{R} \$ \\
11.273 .601,55\end{array}$ & $-39,50 \%$ \\
\hline Total & R\$ 156.587.197,82 & $\mathrm{R} \$ 124.560 .335,30$ & $\begin{array}{c}\mathrm{R} \$ \\
32.026 .862,52\end{array}$ & $-20,45 \%$ \\
\hline
\end{tabular}

Fonte: os autores, 2018.

Observa-se que houve aumento da diferença percentual entre o valor do edital e do homologado em três das quatro categorias, apresentando apenas no Objeto Específico (justamente o tipo de processo que representa mais da metade dos processos em 2018) diminuição na economia do certame, caindo de $21,53 \%$ para $14,84 \%$. Os processos do tipo Registro de Preço apresentam maior variação na diferença, subindo de 34,6\% em 2017 para 39,5\% em 2018. 


\section{Diferença Percentual entre Valor do Edital e Homologado}

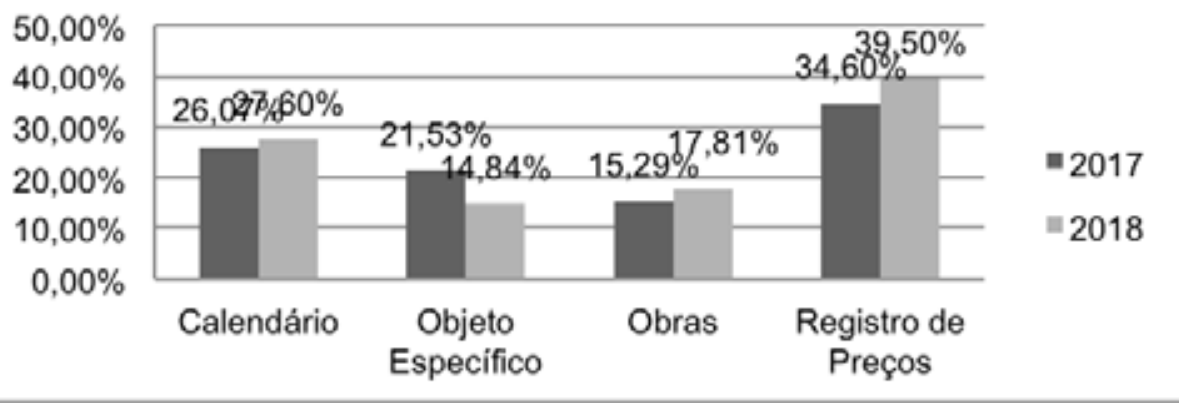

Fonte: os autores, 2018.

Percebe-se que os processos de Registro de preço são os que obtêm maior economia em ambos os anos, de $34,60 \%$ e $39,50 \%$, respectivamente. Os processos que têm menor economia em 2017 são os de Obras, com 15,29\%, enquanto em 2018 o Objeto Específico passa a representar a menor taxa, com 14,84\% de economia. Apesar do percentual de economia geral ter caído em 2018, o montante economizado passa de $R \$ 5.571 .839,12$ em 2017 para $R \$ 313.174 .395,64$ no período de janeiro a agosto.

\subsection{Itens homologados}

A análise de itens homologados estabeleceu-se por meio do Relatório do Pregão gerado após o certame, no qual se evidenciam os lotes de itens homologados e malsucedidos, que podem ocorrer de duas maneiras: a primeira são os itens fracassados, que são itens que receberam propostas, mas não foram adjudicadas por não atenderem a algum critério do edital; a segunda são os itens desertos, que ocorrem quando estes não recebem nenhum lance.

Tabela 7- Itens Homologados e Malsucedidos de 2017

\begin{tabular}{c|ccc}
\hline Ano & \multicolumn{3}{|c}{2017} \\
\hline Tipo & Homologados & Malsucedidos & Proporção de Malsucedidos \\
\hline Calendário & 91 & 26 & $28,57 \%$ \\
Objeto Específico & 559 & 63 & $11,27 \%$ \\
Obras & 10 & 0 & $0,00 \%$ \\
Registro de Preço & 758 & 53 & $6,99 \%$ \\
\hline Total & $\mathbf{1 4 1 8}$ & $\mathbf{1 4 2}$ & $\mathbf{1 0 , 0 1 \%}$
\end{tabular}

Fonte: os autores, 2018. 
Tabela 8- Itens Homologados e Malsucedidos de 2018

\begin{tabular}{c|ccc}
\hline Ano & \multicolumn{3}{|c}{2018} \\
Tipo & Homologados & Malsucedidos & Proporção de Malsucedidos \\
\hline Calendário & 705 & 183 & $25,96 \%$ \\
Objeto Específico & 1028 & 191 & $18,58 \%$ \\
Obras & 32 & 1 & $3,13 \%$ \\
Registro de Preço & 1114 & 201 & $18,04 \%$ \\
\hline Total & $\mathbf{2 8 7 9}$ & $\mathbf{5 7 6}$ & $\mathbf{2 0 , 0 1 \%}$
\end{tabular}

Fonte: os autores, 2018.

Nas Tabelas 7 e 8, apresentam-se a quantidade de itens previstos em edital e malsucedidos por modalidade em 2017 e 2018. Observa-se que o número de itens nos editais em 2017 é menor nos quatro tipos de processos. Apenas o Calendário tem queda na proporção de itens malsucedidos em 2018 em relação a 2017.

Gráfico 4- Proporção entre Itens Malsucedidos e Homologados

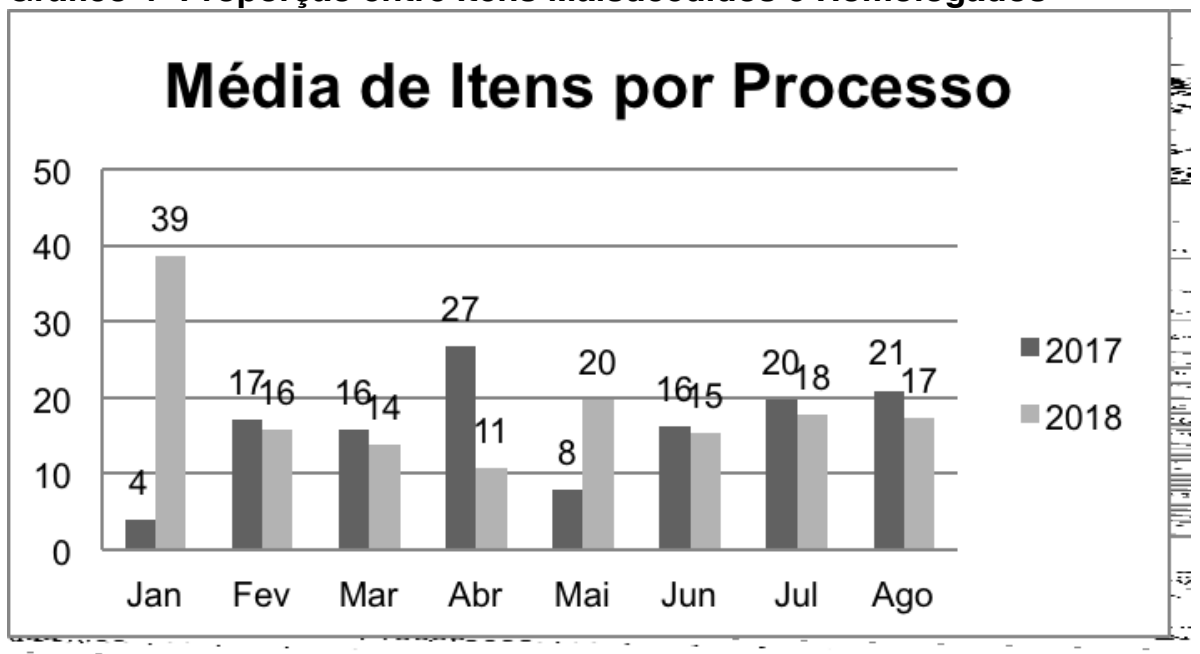

Fonte: os autores, 2018.

A proporção de itens malsucedidos em relação aos itens que constavam no edital para serem arrematados foi maior em 2018 do que em 2017 em sete dos oito meses de análise. O mês de Agosto de 2017 apresenta maior relação de itens fracassados ou desertos, com 30,77\%. No mês de Fevereiro de 2017 não houve itens malsucedidos, fato que não ocorreu em 2018. O mês com menor variação percentual entre os anos foi Março, que passa de $21,15 \%$ para $23,53 \%$, enquanto o mês com maior variação foi o de Maio, que passa de 2,17\% para $27,48 \%$. 


\subsection{Relação de quantidade de itens e processos}

Um dos fatores de eficiência das licitações é a unificação de pedidos de itens semelhantes em um mesmo processo, considerando-se tanto itens de uma mesma secretaria demandante como itens equivalentes, que são requisitados por secretarias diferentes. Desta forma, a SMGP diminui o volume de processos em andamento e realiza menos certames, que por sua vez licitarão mais itens de uma só vez. Portanto, avaliam-se a seguir, no Gráfico 5, a média de itens licitados por processos no primeiro quadrimestre de 2017 e 2018.

\section{Gráfico 5 - Média de Itens por Processo}

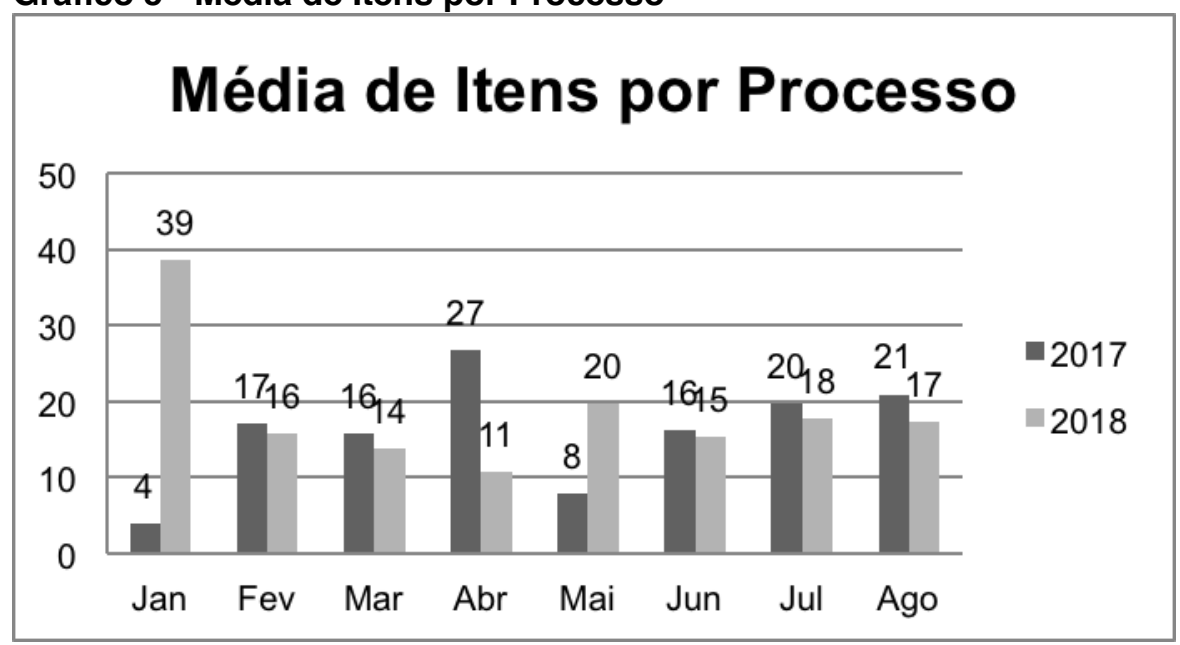

Fonte: os autores, 2018.

Observa-se que a média de itens por processo manteve-se semelhante nos anos de 2017 e 2018, 17 e 18 itens respectivamente. Porém, esse aumento na média de itens por processo deve-se ao mês de janeiro e maio, que são os únicos que apresentam maior média no ano de 2018. Os outros seis meses têm média maior em 2017.

\subsection{Comparação da quantidade de itens e processos}

$\mathrm{Na}$ Tabela 9, comparam-se as variações percentuais entre o número de itens e o número de processos licitatórios de um ano para o seguinte. 
Tabela 9- Variação percentual de $\mathbf{N}^{\circ}$ de Itens e $\mathbf{N}^{\circ}$ de Processos

\begin{tabular}{c|ccc|ccc}
\hline Mês & $\begin{array}{c}N^{\circ} \text { Itens } \\
2017\end{array}$ & $\begin{array}{c}N^{\circ} \text { Itens } \\
2018\end{array}$ & $\begin{array}{c}\text { Variação } \\
17-18\end{array}$ & $\begin{array}{c}N^{\circ} \\
\text { Processos } \\
2017\end{array}$ & $\begin{array}{c}\text { No Processos } \\
2018\end{array}$ & $\begin{array}{c}\text { Variação } \\
17-18\end{array}$ \\
\hline Jan & 39 & 771 & $1876,92 \%$ & 10 & 21 & $100,00 \%$ \\
Fev & 68 & 221 & $225,00 \%$ & 4 & 14 & $250,00 \%$ \\
Mar & 189 & 399 & $111,11 \%$ & 12 & 29 & $141,67 \%$ \\
Abr & 373 & 248 & $-33,51 \%$ & 14 & 24 & $64,29 \%$ \\
Mai & 47 & 334 & $610,64 \%$ & 6 & 17 & $183,33 \%$ \\
Jun & 211 & 459 & $117,54 \%$ & 13 & 30 & $130,77 \%$ \\
Jul & 353 & 623 & $76,49 \%$ & 18 & 35 & $94,44 \%$ \\
Ago & 272 & 414 & $52,21 \%$ & 13 & 24 & $84,62 \%$ \\
\hline Total/ & 1552 & 3469 & $379,55 \%$ & 90 & 194 & $131,14 \%$ \\
Média & & &
\end{tabular}

Fonte: os autores, 2018.

Por meio da comparação da variação percentual de número de processos e de número de itens, é possível avaliar se a SMGP obteve melhora na eficiência em quantidade de processos homologados ou em unificação de licitação de itens num mesmo processo. Constata-se que a variação percentual é similar, de $124,18 \%$ para o número de itens e de $120 \%$ no número de processos.

Por meio da Tabela 9, observa-se que a variação de número de itens entre os anos de 2017 e 2018 foi extremamente maior em Janeiro, fato que só ocorre neste mês. Em Abril, o número de processos cresceu, enquanto o número de itens caiu $33,51 \%$. Em cinco dos oito meses, o número de processos tem aumento de pelo menos $100 \%$, isto é, dobra.

\subsection{Discussão dos dados}

A partir dos dados obtidos, observa-se que há inserção de princípios advindos do NPM, tais como expostos por Sechi (2009) ou referidos em Pieranti, Rodrigues e Peci (2007) a respeito das dicotomias da Nova Gestão Pública e do atendimento às necessidade do cliente-cidadão na gestão municipal de Londrina, já que há aumento da eficiência nos prazos médios de tramitação dos processos, que cai de 190 em 2017 para 154 dias em 2018. Isto faz com que haja maior giro dos processos pela SMGP. Entretanto, a eficácia dos processos não obteve os mesmos resultados, uma vez que houve aumento no número de itens malsucedidos em 2018.

Conforme referido em Faria et al (2010) e por Tridapalli e Borinelli (2015) como um desafio à gestão municipal, a especificidade do objeto tem efeito contrá- 
rio na economia da compra pública, o que é observado no presente estudo pelo índice de economia dos processos de Objeto Específico, que passa de -21,53\% em 2017 para $-14,84 \%$ em 2018 na diferença entre o valor homologado e o valor máximo do edital.

Outra mudança sugerida e descrita por Faria et al (2010) é como o agrupamento das demandas pode ser constatada na média de itens por edital, a qual tem pequeno aumento em 2018 , sendo que a variação de número de itens entre os dois anos é de $379,55 \%$, enquanto a variação no número de processos é de $131,14 \%$.

\section{CONSIDERAÇÕES FINAIS}

O objetivo geral da pesquisa foi avaliar a evolução dos processos licitatórios homologados do município de Londrina nos dois primeiros quadrimestres de 2018 e 2017. Para tanto, também foram determinados três objetivos específicos:

I. Descrever os tipos de processos licitatórios que foram analisados;

II. Definir as fases que o processo percorre até a homologação;

III. Realizar uma análise estatística descritiva dos processos homologados no primeiro quadrimestre de 2018 em Londrina.

Quanto ao primeiro objetivo, foram estabelecidos quatro tipos: Calendário, Objeto Específico, Obras e Registro de Preços. Em relação ao segundo objetivo, são sete fases pelas quais os processos passam: realização de check-list, abertura de PAL, solicitação de consulta jurídica na PGM, parecer jurídico, prazo para publicação do edital: publicação do edital do JOM, prazo entre publicação e certame, prazo entre certame e homologação e o prazo total dos processos.

Conforme o último objetivo específico, relacionado à análise descritiva dos processos homologados, a pesquisadora pôde concluir que: há aumento no número de processos homologados no período analisado de 2018 em relação ao de 2017. Há diminuição da economia percentual dos certames em 2018, sendo que esta diferença deve-se principalmente aos processos de Objeto Específico, que justamente representam o maior volume de processos da SMGP. Quanto à relação entre itens do edital e itens homologados e malsucedidos, constata-se aumento no número de itens homologados em sete dos oito meses analisados de 2018. Por último, há também aumento nos itens que são malsucedidos nos certames no período, cujas causas devem ser investigadas e esclarecidas como sugestão de outros estudos. 
Entretanto, a Prefeitura de Londrina, em especial a Secretaria Municipal de Gestão Pública, em ambos os anos, observou a economia em relação aos valores de edital, por mais que a economia de 2018 (20,45\%) tenha sido menor do que em 2017 (25,51\%). Em resposta ao objetivo geral da pesquisa, é possível afirmar que houve melhora na eficiência do trabalho da secretaria, pois os prazos médios diminuíram e houve aumento no número de processos homologados por mês.

A presente pesquisa apresenta como contribuição prática para o município estudado, mais especificamente junto à Secretaria de Gestão Pública, a otimização dos processos licitatórios, diminuindo os prazos para a conclusão destes, unificando demandas de diferentes secretarias, bem como obtendo uma melhor economicidade dos itens adquiridos.

Sugere-se para pesquisas futuras realizar o acompanhamento dos preços não somente por meio da comparação entre o valor dos editais e os homologados, mas sim junto à variação dos preços dos itens comprados em diferentes períodos no mesmo órgão, assim como em outras bases de dados de compras públicas.

\section{REFERÊNCIAS}

Blonski, Fabiano; Prates, Rodolfo Coelho; Costa, Mayla; VIZEU, Fábio. (Janeiro/ Março, 2017). O Controle Gerencial na Perspectiva do New Public Management: o caso da adoção do Balanced Scorecard na Receita Federal do Brasil. Administração pública gestão social, 9(1), 1-74. Recuperado de http:// www.apgs.ufv.br/index.php/apgs/article/view/1042/html\#.WtYi8i7wbIU.

Bresser-Pereira, Luiz Carlos (2009). Construindo o Estado Republicano: democracia e reforma da gestão pública. (1. ed.). Rio de Janeiro: Editora FGV.

Câmara dos deputados. (2017). Legislação sobre Licitações e Contratos Asministrativos. Lei $n^{\circ}$ 8.666, de 21 de junho de 1993, que regulamenta o art.37, inciso XXI da Constituição Federal e Legislação Correlata. (5 ed.). Brasília: Edições Câmara.

Faria, Evandro Rodrigues; Ferreira, M. A. Marques; Dos Santos, Lucas Maia; Silveira, Suely de Fátima Ramos. (Novembro/Dezembro, 2010). Fatores determinantes na variação dos preços dos produtos contratados por pregão eletrônicos. Revista de Administração Pública.

IBGE. (2010). Indicadores Sociais Municipais 2010: Uma análise dos resultados dos resultados do universo do censo demográfico de 2010. Recuperado de https://ww2.ibge.gov.br/home/presidencia/noticias/imprensa/ppts/00000006 475711142011571416899473.pdf. 
IBGE. LONDRINA. Brasil, Paraná, Londrina. Recuperado de https://cidades.ibge. gov.br/brasil/pr/londrina.

Marconi, Marina de Andrade; Lakatos, Eva Maria (2003). Fundamentos de Metodologia Científica. (5. ed.). São Paulo: Atlas.

MEMORIA TRF4. (2014) SEI. Recuperado de http://memoria.trf4.jus.br/memoria/ controlador.php?acao=pagina_visualizar\&id_pagina=1271 .

Ministério da Fazenda. (2017). SEl: Sistema Eletrônico de Informações. Recuperado de http://www.fazenda.gov.br/sei

Motta, Ronaldo Seroa da; Moreira, Ajax (2007). Eficiência na gestão municipal do Brasil. IPEA, Texto para discussão n¹301. Recuperado de http://www.ipea. gov.br/portal/images/stories/PDFs/TDs/td_1301.pdf.

Osborne, Stephen P. The new public governance? Public Management Review. United Kingdom. 8. Recuperado de: http://spp.xmu.edu.cn/wp-content/uploads/2013/12/the-New-Public-Governance.pdf

Perfil do Município de Londrina: Ano base 2017. Recuperado de http://www1.Iondrina.pr.gov.br/dados/images/stories/Storage/sec_planejamento/perfil/Perfil_2017.pdf.

Pieranti, Octavio Penna; Rodrigues, Silva; Peci, Alketa (2007). Governança e New Public Management: Convergências e Contradições no Contexto Brasileiro, 1-16. Rio de Janeiro, XXXI Encontro Anpad.

Richardson, Roberto Jarry; Peres, José Augusto de Souza; Wanderley, José Carlos Vieira; Correia, Lindoia Martins, Peres, Maria de Holanda de Melo (2015). Pesquisa Social: métodos e técnicas, (3 ed.). São Paulo: Atlas.

Ribeiro, Cássio Garcia; Júnior, Edmundo Inácio (Dezembro, 2014). Mensurando o mercado de compras governamentais brasileiro. Caderno Finanças Públicas, 14, 265-287.

Secchi, Leonardo (Março/Abril, 2009,). Modelos organizacionais e reforma da administração pública. Revista de Administração Pública, 43, 347-369.

Tridapalli, Juarez Paulo; Borinelli, Benilson (2015). Compras públicas: divergências de preços praticados entre os níveis de governo e o mercado privado no estado do amazonas. Brasília, VIII Congresso CONSAD de Gestão Pública.

Tridapalli, J.; Suguihiro, L. T.; Amâncio-Vieira, S. F.; Secorum, L.; Silva, F. C. E. (2018). Public Procurement: a Model Designed for Medium-Sized Cities in the Brazilian Context, 1-16. In: 8th International Public Procurement Conference - IPPC8.

Vignoli, Francisco Humbert (2008, Março). Poder local e o desenvolvimento mu- 
COMPRAS PÚBLICAS:

UMA ANÁLISE DOS PROCESSOS LICITATÓRIOS HOMOLOGADOS NO MUNICÍPIO DE LONDRINA-PR

nicipal. Cadernos FGV Projetos. São Paulo, 4(8), 15-20. Recuperado de https://bibliotecadigital.fgv.br/dspace/bitstream/handle/10438/6914/312. pdf? sequence=1\&isAllowed=y

Yin, R. K (2005). Estudo de caso: planejamento e métodos. (3 ed.). Porto Alegre: Bookman. 